\title{
Peningkatan Pengetahuan Gempa dan Kemampuan Mitigasi Pada Siswa Disabilitas Kota Gorontalo Melalui Program Mie Titi
}

\author{
Reskiyanto Fauzi Duwingik, Della Nawarita P. Kasim, Dewi Ayu, Moh. Aristo \\ Dano, Intan Noviantari Manyoe \\ Geological Engineering Major, Departement Of Earth Science and Technology, \\ Faculty Of Mathematics and Natural Science, Universitas Negeri Gorontalo \\ reskieki50@gmail.com
}

\begin{abstract}
Abstrak
Kondisi Kota Gorontalo memiliki tingkat kerentanan yang tinggi terhadap bahaya gempa bumi, oleh karena itu pemahaman tentang gempa bumi perlu dilakukan sejak dini, terutama bagi anak-anak penyandang disabilitas. MIE TITI bertujuan untuk meningkatkan pengetahuan dan kemampuan mitigasi gempabumi bagi siswa disabilitas di SDLB Kota Gorontalo, khususnya tunanetra, tunarungu, dan tunagrahita. Metode yang akan digunakan adalah metode fun learning dengan instrumen yang digunakan berupa MINING (Music Fun Learning), MICARD (Mitigation Flascard), MINAME (Mitigation of Nature Game) dan MIGAS (Mitigation Praise). Sampel sebanyak 34 orang penyandang disabilitas di SDLB Kota Gorontalo yang terdiri dari siswa tunanetra, tunarungu dan tunagrahita. Hasil yang diperoleh adalah terjadinya peningkatan pengetahuan gempa dan kemampuan mitigasi gempa pada siswa disabilitas dimana pada anak tunanetra sebesar 50\% dan 35\%, tunarungu sebesar $45 \%$ dan $55 \%$, dan tunagrahita sebesar 3\% dan $2 \%$.
\end{abstract}

Kata Kunci: Mitigasi, Gempa, Fun Learning, Disabilitas, Gorontalo.

\begin{abstract}
The condition of Gorontalo City has a high level of vulnerability to earthquake hazards, therefore understanding of earthquakes needs to be done early on, especially for children with disabilities. MIE TITI aims to increase earthquake mitigation knowledge and ability for students with disabilities at SDLB Gorontalo City, especially the visually impaired, deaf, and mentally disabled. The method to be used is a fun learning method with instruments used in the form of MINING (Music Fun Learning), MICARD (Mitigation Flascard), MINAME (Mitigation of Nature Game) and Oil and Gas (Mitigation Praise). A sample of 34 people with disabilities in Gorontalo City SDLB consisted of blind, deaf and retarded students. The results obtained are an increase in earthquake knowledge and earthquake mitigation ability in students with disabilities where in children with visual impairment by $50 \%$ and $35 \%$, deaf by $45 \%$ and $55 \%$, and mental retardation by $3 \%$ and $2 \%$.
\end{abstract}

Keywords : Mitigation, Earthquake, Fun Learning, Disability, Gorontalo. 


\section{PENDAHULUAN.}

Sesar Gorontalo merupakan sesar besar yang memotong wilayah Kota Gorontalo serta melintasi Danau Limboto (Pasau et al, 2014). Menurut Bahri (2011), sesar Gorontalo memiliki arah rata-rata sebesar $\mathrm{N} 125^{\circ} \mathrm{E} / \mathrm{N} 305^{\circ} \mathrm{E}$ dimana sesar utama yang semula terbentuk sebagai sesar mendatar dekstral pada Neogen Akhir, kemudian teraktifkan kembali sebagai sesar mendatar sinistral. Peta Deliniasi kelurusan menunjukkan bahwa SDLB terletak di zona sesar Goronatalo.

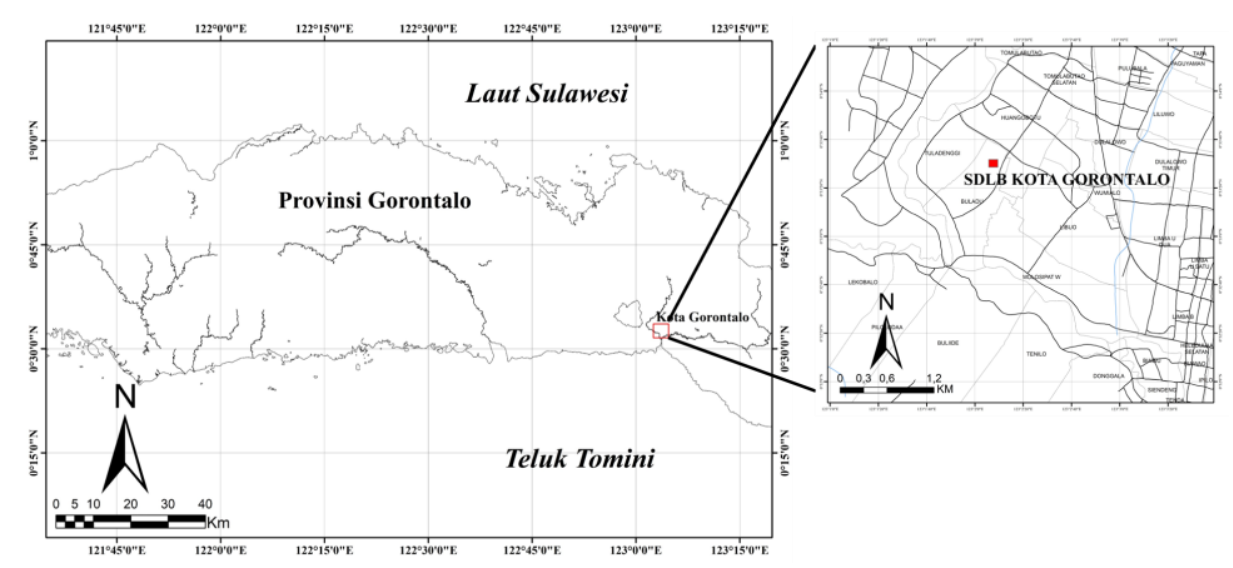

Gambar 1. Lokasi SDLB Kota Gorontalo.

Menurut Manyoe et al (2019), Provinsi Gorontalo dikategorikan sebagai daerah dengan tingkat kerusakan gempa ringan hingga sedang. Gempabumi di Gorontalo terjadi karena subduksi Laut Sulawesi dan patahan aktif di Gorontalo. Selain itu tingkat percepatan tanah maksimum wilayah Gorontalo sebesar 1.462 - 99.714 gal. Untuk itu perlu adanya peningkatan kemampuan mitigasi terhadap gempa bumi.

Belajar dari gempa yang terjadi di Palu, jumlah penyandang disabilitas yang terdaftar di balai rehabilitas sosial penyandang disabilitas intelektual Nipotowe sebanyak 359 orang, tetapi yang selamat hanya 70 orang. Menurut Duwingik et al (2019) kemampuan mitigasi pada anak-anak penyandang disabilitas khususnya tunanetra, tunarungu, dan tunagrahita pada SDLB kota Gorontalo masih sangat rendah, untuk itu perlu adanya peningkatan kemampuan mitigasi dengan cara yang tepat dan metode belajar yang ceria. 


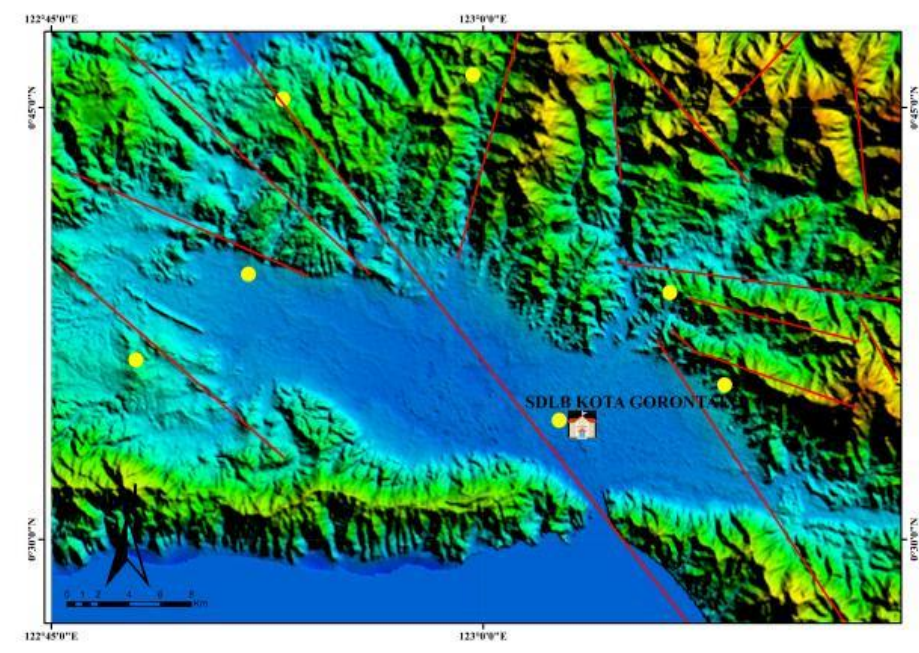

Gambar 2. Peta deliniasi kelurusan di Kota Gorontalo.

Penerapan ini bertujuan untuk meningkatkan pengetahuan dan kemampuan mitigasi gempa pada siswa disabilitas khususnya tunanetra, tunarungu, dan tunagrahita pada SDLB kota Gorontalo dengan menerapkan program MIE TITI (Mitigation of Earthquake Disaster for Disability) sehingga dapat meminimalisir resiko ataupun dampak yang dihasilkan oleh gempa.

\section{METODE}

Metode yang digunakan adalah metode fun learning berupa MIE TITI yang diterapkan langsung kepada anak-anak penyandang disabilitas di SDLB Kota Gorontalo dengan total sampel 34 orang dimana sampel yang digunakan melibatkan seluruh populasi yang terdiri dari tunanetra sebanyak 2 orang, tunarungu 25 orang, dan 7 orang tunagrahita. Instrumen yang digunakan adalah MINING (Music Fun Learning), MICARD (Mitigation Flascard), MINAME (Mitigation Of Nature Game) dan MIGAS (Mitigation Praise). Setelah penerapan MIE TITI dilakukan post test untuk mengetahui pengetahuan dan kemampuan mitigasi gempa pada siswa. Berdasarkan hasil post test, skor total setiap penyandang cacat dihitung menggunakan rumus:

$$
X=\frac{\sum x}{n} \times 100 \%
$$

Information:

$X \quad$ : Average score

$\Sigma \mathrm{x} \quad$ : Number of Scores

$\mathrm{N}$ : Number of Respondents 
Table 1. Table of Student Response level (Azwar, 2011).

\section{$\mathbf{X}$}

$$
\begin{gathered}
80 \% \leq X \leq 100 \% \\
60 \% \leq X<100 \% \\
40 \% \leq X<100 \% \\
20 \% \leq X<40 \% \\
X<20 \%
\end{gathered}
$$

\section{Category}

Very Good

Good

Good enough

Poor

Not Good

\section{HASIL DAN PEMBAHASAN}

MIE TITI ditujukan untuk peningkatan pengetahuan dan mitigasi gempa pada anak-anak penyandang disabilitas khususnya tunanetra, tunarungu, dan tunagrahita. MIE TITI menerapkan metode fun learning yang terdiri dari MINING (Music Fun Learning), MICARD (Mitigation Flascard), MINAME (Mitigation Of Nature Game) dan MIGAS (Mitigation Praise).

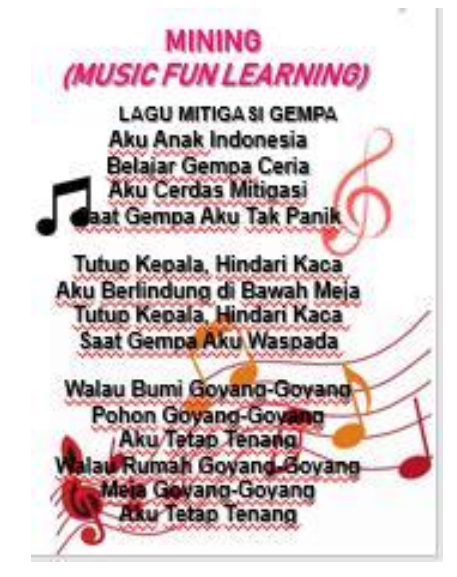

Gambar 3. MINING (Music Fun Learning).

MINING (Music Fun Learning ) merupakan sebuah lagu ceria, berisi tentang tatacara mitigasi gempa yang ditujukan untuk anak-anak penyandang tunanetra. MICARD (Mitigation Flascard) berupa kartu dengan tampilan menarik mengenai tatacara mitigasi gempa untuk anak-anak tunarungu. sedangkan MINAME (Mitigation Nature Game) dan MIGAS (Mitigation Praise) merupakan permainan sekaligus ajang pemberian hadiah/penghargaan yang ditujukan kepada anak-anak tunagrahita untuk meningkatkan pengetahuan dan kemampuan serta membangun kepercayaan diri mereka. 


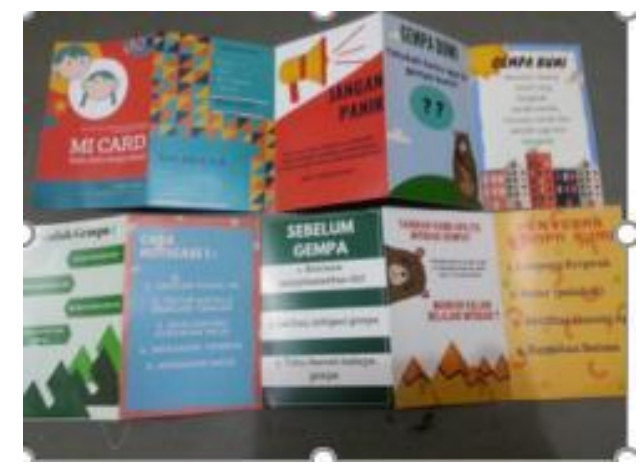

Gambar 4. MICARD (mitigation flascard).

Sebelum menerapkan MIE TITI telah dilakukan beberapa kegiatan awal yang diawali dengan pelaksanaan FGD bersama para guru untuk mengetahui perilaku dan kebiasaan dari anak-anak penyandang tunanetra, tunarungu, dan tunagrahita. Selanjutnya perkenalan pada anak-anak untuk melakukan pendekatan emosional, dan terakhir melakukan terapi sosial kepada penyandang tunagrahita.

Setelah pelaksanaan program MIE TITI pada anak-anak penyandang tunanetra, tunarungu, dan tunagrahita di SDLB kota Gorontalo, terjadi peningkatan pengetahuan dan kemampuan mitigasi gempa pada masingmasing penyandang disabilitas. Pada penyandang tunanetra terjadi peningkatan pengetahuan gempa sebesar 50\% dan kemampuan mitigasi gempa 35\%. Hal ini dipengaruhi oleh kemampuan pendengaran mereka yang baik sehingga mereka mudah menyerap materi yang disampaikan melalui mining (music fun learning) dengan cepat dan baik. Pada anak-anak penyandang tunarungu pengetahuan gempa meningkat 45\% sedangkan kemampuan mitigasi meningkat sebesar 65\%. Peningkatan ini dipengaruhi oleh kemampuan melihat mereka yang baik sehingga mampu menyerap setiap materi yang diberikan melalui micard (mitigation flascard). Sedangkan untuk anak-anak penyandang tunagrahita terjadi peningkatan pengetahuan dan kemampuan mitigasi sebesar 3\% dan 2\%.

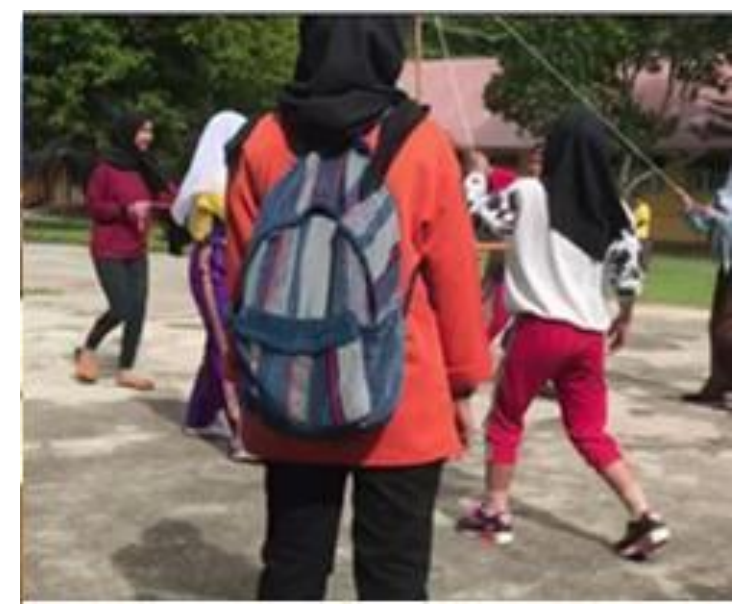

Gambar 5. MINAME (Mitigation Nature Game). 


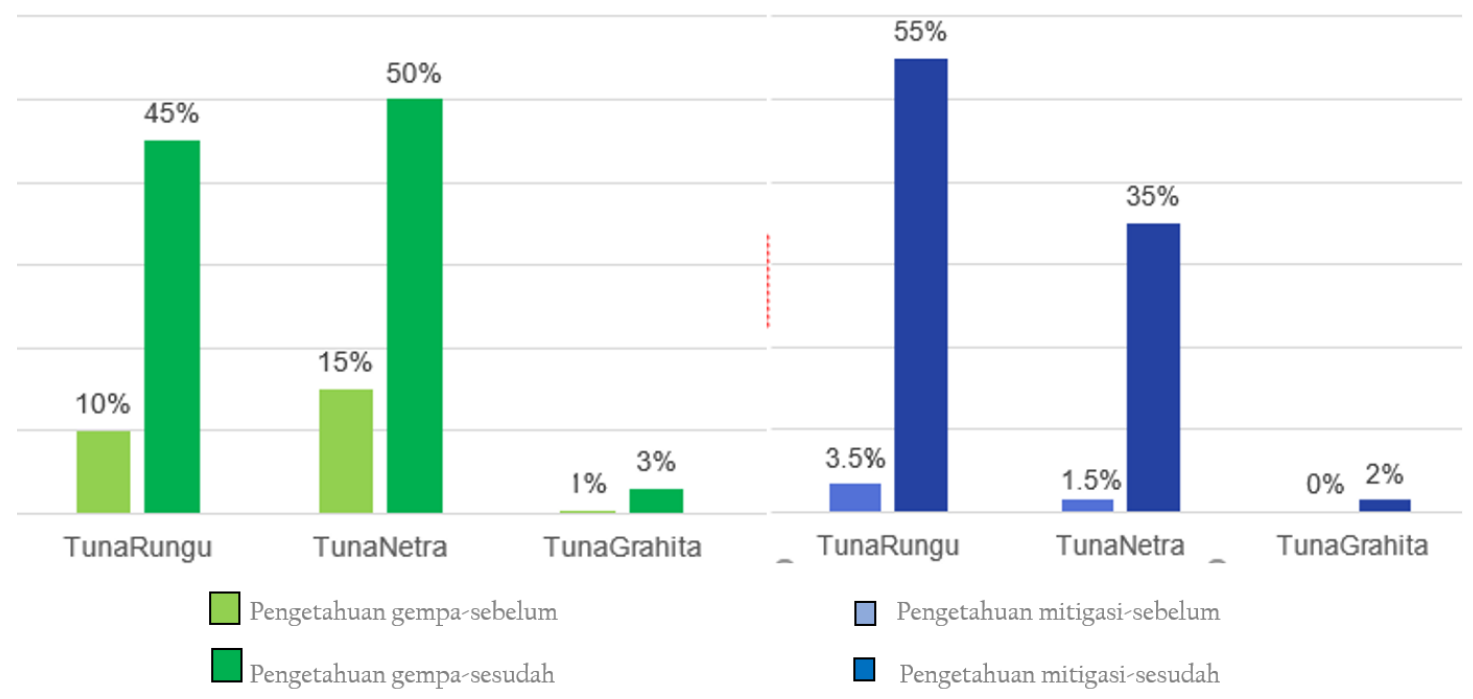

Gambar 6. Diagram peningkatan pengetahuan gempa dan kemampuan mitigasi pada siswa disabilitas SDLB Kota Gorontalo.

\section{KESIMPULAN}

Program MIE TITI mampu meningkatan pengetahuan dan kemampuan mitigasi gempa pada penyandang tunanetra, tunarungu, dan tunagrahita. Pada anak tunanetra sebesar 50\% dan 35\%, tunarungu sebesar $45 \%$ dan 55\%, dan tunagrahita sebesar 3\% dan 2\%. Perlu terus dilakukan pemberian materi secara berulang-ulang serta melakukan beberapa kali post test untuk mengukur peningkatan pengetahuan dan kemampuan mitigasi pada anakanak penyandang tunanetra, tunarungu, dan tunagrahita.

\section{UCAPAN TERIMAKASIH}

Penulis mengucapkan terima kasih kepada RISTEKDIKTI atas dukungan dana melalui program kreativitas mahasiswa (PKM). Terimakasih penulis ucapkan kepada para guru-guru disabilitias di lingkungan SDLB kota Gorontalo, PKM UNG, dan Laboratorium Teknik Geologi John Ario Katili. 


\section{DAFTAR PUSTAKA}

Manyoe, I. N., Arif, S., \& Lahay, R. J. (2019). Earthquake Damage Level of Gorontalo Area Based on Seismicity and Peak Ground Acceleration. Jambura Geoscience Review, 1(1), 7-12.

Pasau, G., \& Raharjo, S. S. (2014). Identifikasi Sesar di Wilayah Gorontalo dengan Analisis Mekanisme Bola Fokus. Jurnal MIPA, 3(1), 40-43.

Bachri, S. "STRUCTURAL PATTERN AND STRESS SYSTEM EVOLUTION DURING NEOGENE-PLEISTOCENE TIMES IN THE CENTRAL PART OF THE NORTH ARM OF SULAWESI." Jurnal Geologi dan Sumberdaya Mineral 21.3 (2011): 127-135.

Duwingik, Reski Fauzi, et al. "SURVEY AND EFFORTS TO IMPROVE MITIGATION ABILITY FOR DISABILITY STUDENTS IN GORONTALO CITY." Jurnal Sains Informasi Geografi 2.1 (2019): 40-43. 